\title{
Speaking skills in scientific English: Intelligibility, redundancy and compensation strategies
}

Jonathan Upjohn, Diana Amadis and Marie-Hélène Fries-Verdeil

\section{CpenEdition}

\section{Journals}

Electronic version

URL: http://journals.openedition.org/asp/3582

DOI: $10.4000 / a s p .3582$

ISSN: 2108-6354

\section{Publisher}

Groupe d'étude et de recherche en anglais de spécialité

\section{Printed version}

Date of publication: 1 December 1996

Number of pages: 295-305

ISSN: 1246-8185

\section{Electronic reference}

Jonathan Upjohn, Diana Amadis and Marie-Hélène Fries-Verdeil, « Speaking skills in scientific English: Intelligibility, redundancy and compensation strategies », ASp [Online], 11-14 | 1996, Online since 10 May 2013, connection on 01 May 2019. URL : http://journals.openedition.org/asp/3582 ; DOI :

$10.4000 / a s p .3582$

This text was automatically generated on 1 May 2019.

Tous droits réservés 


\section{Speaking skills in scientific English: Intelligibility, redundancy and compensation strategies}

Jonathan Upjohn, Diana Amadis and Marie-Hélène Fries-Verdeil

1 Speaking Skills in Scientific English (SSSE) is the third book in the series which started with Minimum Competence in Scientific English (MCSE).The series addresses the problem of teaching English for scientific purposes within the context of the French university system.

2 What we would like to do in this paper is to give a brief overview of the background to the series followed by an analysis of some real data, this will be followed by a discussion in more detail of the issues which guided the design of the present volume. More specifically, we will examine the notions of intelligibility, redundancy, compensation strategies. Finally we will draw conclusions about the model of English which is most appropriate for a student to learn.

\section{Minimum Competence in Scientific English}

The series currently consists of the following elements:

- Minimum Competence in Scientific English + Software : Lexis, Enigma 1 (Graph description), Enigma 2 (Process description)

- Listening Competence for Scientific English

- Speaking Skills for Scientific English (January 1997)

Minimum Competence in Scientific English was first published in 1991. Despite its many failings, MCSE has had a considerable success within the university and the research community, with sales now approaching 20,000. This first volume is concerned above all with the fundamental problem of primary reading skills in 1st and 2nd year university studies. From the start, the series aim was to provide the learner with two things; in the first place, it establishes a check list of those linguistic items which it is absolutely 
essential for the learner to master so that the learner may have a crystal clear perception of his learning task. In so far as MCSE is concerned, this consists of a pre-scientific core lexis of 750 words and a restricted selection of communicative functions. Secondly, it provides a learning tool that can be used autonomously so that any student who desires to make progress has the necessary equipment at his disposal.

5 The second book, Listening Competence in Scientific English, as its name implies, is concerned with aural skills. It is complementary to MCSE and is designed for the same linguistic level and within exactly the same lexical and functional framework.

6 This final volume, Speaking Skills in Scientific English, islinguistically more ambitious. It is the inevitable outcome of the other two and provides support for those who wish to attain proficiency in presenting papers or research results at conferences in English.

7 The series MCSE has been concerned above all with finding practical solutions to concrete questions. It may be a truism, but one that is perhaps neglected, that much of the underachieving in university language learning can be put down to either fuzziness in so far as aims are concerned, or to a lack of appropriate tools which might enable the learner to accomplish what he is in fact supposed to do. Students can be helped enormously merely by having a clear definition of what they need to learn accompanied by the wherewithal to do it. It may be objected that general statements of this sort are easy enough to make but can often be vacuous - they need therefore, to be illuminated by concrete examples.

8 Within the context of the present volume, SSSE, we would argue that two reasons for under-achievement in pronunciation are that:

1. at the beginning of the year, not one student is aware that the schwa is the most common vowel in the English language.

2. virtually no student is aware, or will indeed believe, that faulty stress can be more devastating to communication than faulty grammar.

9 As Leeson (1975) remarks, it is rare for learners to understand the real nature of language. Is it not then inevitable that the student's learning priorities will not fit his learning needs? We would add, that the definition of clear and limited learning aims is also one of the greatest aids to motivation and hence to learning as the learner can see that his goal is attainable.

\section{Intelligibility}

One of the main limiting factors that must be taken into consideration in language teaching in a university is the ferocious competition for the learner's time. Young scientists especially, have very little of it to spare. Speaking Skills for Scientific English attempts, therefore, to put at the learner's disposal material that has been pre-selected in terms of communicative usefulness, material that is organised to help students learn fast and efficiently and with a minimum of, what Higgins (1988) calls, "unnecessary labour".

11 The book addresses the problem of public speaking skills, a compulsory hurdle for many of our students and one which is particularly daunting as it is a situation where they are at their most vulnerable. At their most vulnerable, for their intelligibility as non-native speakers cannot be taken for granted while, at the same time, they find themselves in a 
situation where their intelligibility is crucially important in terms of their professional identity.

This whole area of intelligibility however, is one which in standard monolingual teaching courses is too frequently neglected - and particularly so in short courses. At first sight this may seem paradoxical - it would seem logical that language teaching and meaning must of necessity be inseparable bed-fellows. How can we account for the fact that intelligibly and pronunciation are the poor cousins of the language classroom?

There are several reasons that can explain this. In the first place the neglect is specifically linked to classroom processes and classroom dynamics. In the age-old struggle between form and content, "praxis" always loads the dice heavily in favour of content, - all the more so within the confines of the modern classroom with its communicative paradigm. Here, "form" is inevitably the "plain Jane" and all the glamour is with semantics. ${ }^{1}$.

Another reason is that, unlike comprehension or grammar, there is within the classroom no clear benchmark of intelligibility. Competence of this sort is on a cline and simple binary decisions of right and wrong cannot be easily applied. This makes "intelligibility" all the more difficult to explain, to teach and to evaluate.

Doubtless too, is the fact that as teachers, we spend too much of our time within the classroom and our perceptions may grow dull and frayed. We become bad judges - worse we may in fact become unwitting accomplices, agents in aiding and abetting the development of bad language habits (Kenworthy 1987). Attempts to mitigate the accusation by reference to interlanguage do not seem appropriate here. Like the fig leaf, the notion can hide a little but it does not change the underlying nature of things. (It should be remembered that the original formulation by Selinker (1972) presupposed exposure to L1). But here, within the monolingual classroom, the defective language which can develop and is tolerated is more closely allied to fossilisation than interlanguage. It is perhaps worth reminding ourselves, just how far teachers can become estranged to the concept of meaning and intelligibility. This is made starkly clear by the devastating anecdote of the colleague who proudly showed a video of one of her students to a visiting friend from Britain only to hear after a couple of minutes the withering reply,

It's very nice but I'm afraid I don't understand French.

\section{Analysing the Data}

16 If this seems no more than an cruel anecdote, ${ }^{2}$ to remind ourselves just how serious the question of intelligibility can be it will perhaps be useful just to look at a short extract from a video. (During the conference a video extract was shown - the following transcription cannot render the problems of intelligibility that it posed.)

I will present you to PLOM D, which is a / database programming language resu lting from the integration of an / object oriented database programming language and then a / logic programming language. / This work has be done at the Bull research centre in Grenoble, in collaboration with the Grenoble University. / This w ork is part of the Idea-Esprit project. / Our work starts with the ??? [inaudible] / because we think that / object oriented database programming language have a lack in declarativity,/ and logic /deductive programming language are very ap propriate and very useful when / creating a database. / On the other hand the imperative programming languages are needed / when developing applications./ 

Grenoble University who was in a laboratory specialising in automatic translation, ${ }^{3}$ and was doing her research on a new programming language. Although the written text displays a decent grammatical accuracy and a fairly precise command of vocabulary, especially as far as her specialised field of knowledge is concerned, her actual oral performance was almost incomprehensible. In fact, when this video extract was shown at the GERAS conference, the question: "What did you understand?" elicited only laughter. A brief anatomy of this serious breakdown in communication needs to take into account phonemes, word and sentence stress, pausing, and intonation.

The phonemic mistakes (represented in bold character above) can either be ascribed to a direct influence of mother tongue phonemes (for example "result" pronounced like the French "résulte") or to a wrong choice among the array of English phonemes, and "work" pronounced like "walk" is a case in point. These occasional mistakes are accompanied by a quasi-absence of schwas or weak forms in auxiliaries, which distracts attention from the main verb, and disrupts sentence stress.

Coming back to a segmental level, the inappropriate migration of word stress also makes her message difficult to understand. ${ }^{4}$ Her most consistent error pattern is to anticipate and stress words on their first syllable (for example "deductive", "appropriate", "creating"). This might partly be accounted for by a natural anxiety linked to public speaking which urges her to go faster, so that she is carried away by her speech, but a closer look at her pauses (represented by slashes on the transcription) gives a complementary insight. On the whole, pauses are not necessarily used here to signal the end of an idea, but tend to fall haphazardly in the middle of thought groups every time the speaker runs out of breath, or hesitates. When she resumes her talk after a pause, she consistently tends to emphasise the first syllable she pronounces, thereby misplacing word stress.

A closer look at the pauses also displays an occasional lack of falling intonation to signal the end of a thought group. For instance, there should logically have been a pause after "object-oriented database programming language" (1.2-3) and after "Grenoble" (1.4). This overall disruption in the intonation pattern linked with unexpected pauses is matched with the use of a surprisingly constant pitch level for compound nouns (see appendix $\mathrm{n}^{\circ}$ 1). "Database programming language", for example, is recurrently pronounced with exactly the same flat intonation pattern. In other words, it is pronounced in a "mouthful" as one single noun, when a native speaker would most likely have used all three levels of pitch, his voice falling gradually from one word to the next.

21 This brief survey of the pronunciation difficulties encountered in scientific talks emphasises the necessity to cater for specific needs linked to scientific English (i.e. weak forms, intonation patterns in compound nouns for example). It also brings into relief the constant links between segmental and suprasegmental level, from a wrong pronunciation of weak forms in auxiliaries to disrupted sentence stress, or from inadequate pausing to misplaced word stress, therefore calling for a holistic approach. 


\section{Factors influencing intelligibility}

If we look at this question of intelligibility in terms of a formal grid we can see that it depends on a number of different factors, each allowing variable leeway for the teacher to intervene. There are basically four main areas.

1. There are certain areas where the teacher has virtually no influence, as the conditions of production for $\mathrm{L} 1$ and for $\mathrm{L} 2$ are the same.

2. In other areas, production will be necessarily defective but problems can be eradicated rapidly by remedial work.

3. Other areas require long-term investment (i.e. more than the time span allotted for the course.)

4. Finally there are areas where compensatory strategies using different communicative techniques may be used. This may partially counterbalance linguistic weaknesses, thereby ensuring an acceptable level of intelligibility.

In section A in table 1 , we have listed those areas where the intelligibility of what is said lies outside the range of influence of both teacher and speaker.

Table 1

\begin{tabular}{|l|l|}
\hline A & Acoustics \\
& Bullding \\
& Voice \\
& Famillarity with: \\
& the speaker's voice \\
& the subject \\
& the terminology \\
& the rhetoric style \\
\hline
\end{tabular}

By voice, we are referring to an innate personal configuration, related to the size of the vocal cavity, to resonance, to pitch and pitch range and to timbre. ${ }^{5}$

Section B lists those areas where no improvement can be made as, presumably, the performance is already "perfect". In the case of the graphics one may suppose that researchers presenting their work in public are aware of what they are doing and will present OHPs of the quality they judge appropriate. It is not really for the language teacher per se to intervene here (cf. table 2).

Table 2

\begin{tabular}{|l|l|}
\hline B & $\begin{array}{l}\text { Graphics } \\
\text { Grammatical accuracy }\end{array}$ \\
\hline
\end{tabular}

The question of grammatical accuracy is interesting as it leads us to a paradox. The grammatical accuracy of a written paper is liable to be perfect in as much that it will surely have been corrected by a competent speaker. Thus, in so far as the speaker remains close to his written text he is in no linguistic danger. However, paradoxically we will argue that he must abandon this haven of linguistic security. The one thing that the intermediate speaker must not do is to remain dependant on his written text for, if he does, all chance of being comprehensible is jettisoned. However unjust it may seem, the only person who can read his text from end to end and get away with it (although he will in all probability be a boring speaker) is the native speaker. 
In Section C we can see those areas where the learner is liable to have serious linguistic deficiencies. These are the areas where, unless some remedy is found the intelligibility of what is said may be fatally flawed.

Table 3

\begin{tabular}{|c|c|}
\hline C & $\begin{array}{c}\text { Pronunciation: } \\
\text { Segmentals } \\
\text { phonemic accuracy } \\
\text { word stress }\end{array}$ \\
& $\begin{array}{c}\text { Suprasegmentals } \\
\text { sentence stress } \\
\text { rhythm } \\
\text { phrasing } \\
\text { intonation }\end{array}$ \\
\hline
\end{tabular}

These are the perennial areas of difficulty where complete accuracy is difficult and doubtless, for many of our students, unattainable. But, as Gillian Brown (1977) points out, the task of extracting a message from a very imperfect sound signal is, at the best of times, difficult. If we can do it at all, it is because natural language is highly redundant and we can make up for what we do not understand by inference and projection. However, any additional loss in phonological accuracy by the learner means that his level of redundancy will become so low that intelligibility will decline.

of course, it is here that the teacher and material writer must intervene to propose remedial work - this is what teachers are for. We must be modest, however in our expectations as to the degree of change that can be implemented. Many of our students have already been exposed to 800 or so hours of language teaching. How much improvement can we realistically expect within the framework of a 50-hour course? The implication of this is that selection and grading are essential. On the one hand a clear distinction must be made between the aesthetic and the functional - between areas of mere error and areas responsible for communicative blockage. At the same time, teaching must be confined to what can in fact be successfully attained within the time span for the course. To give concrete examples the / $h$ / and the schwa / er / can be mastered relatively quickly. However, there is little hope that learners will rapidly appropriate anything but the simplest intonation patterns. This constitutes a de facto argument for not teaching them. ${ }^{6}$

\section{Compensatory Strategies}

There is another strategy however, that can be adopted -or more exactly a supplementary strategy concurrent with remedial phonology. The decreased redundancy stemming from faulty pronunciation can be compensated for by increasing redundancy at other levels. Adopting compensatory strategies should not be seen as a token of defeat. After all, it is a part of the normal competence of any speaker to elaborate strategies to get round communicative problems (Corder 1983). We do not just have to fall back on ad hoc improvisation in a speaking situation. It is sensible to adopt deliberate anticipatory strategies to counterbalance an inevitably defective production. There are two main ways of doing this. Firstly, the speaker can rely heavily on OHP-based speaking techniques (see table 4). 
Table 4

\begin{tabular}{|c|c|}
\hline D & $\begin{array}{c}\text { OHP based speaking techniques } \\
\text { visual support } \\
\text { demonstration } \\
\text { eye contact } \\
\text { rhetorical style } \\
\text { text independence }\end{array}$ \\
& \\
\hline
\end{tabular}

Clearly, speakers are not obliged to use merely linguistic channels for communication. This is widely recognised and is one of the reasons why the OHP is so widely used. But, if we can make our learners fully aware of the different channels of communication and of the relationship between the linguistic and the visual, it will enable them to exploit the OHP optimally and not just use it, as is so often the case, as an inert addenda to a written talk. The OHP by using another mode of communication raises the level of redundancy and consequently of intelligibility. It is useful for the student to understand this so that he can take most benefit from using the visual as a vector of communication, as well as other channels of interpersonal communication; eye contact, gesture, text independence and using a spontaneous interactive rhetorical style.

\section{Redundancy}

But there is another strategy. A conscious attempt should be made to compensate for the relatively impoverished acoustic message by increasing redundancy at other levels.

Textual clarity can be increased on the one hand, by paying greater attention to cohesive devices. Cohesive devices indicate the underlying links within the fabric of the text, they reveal the textual structure and so increase redundancy. By the extensive use of functions of explicit (rather than implicit) enumeration and clarification, by using repetition and restatement to help express complex ideas, through rhetorical questions and other forms of highlighting, by making the text a flawless example of clarity, the speaker can partly compensate for phonological weaknesses.

Table 5

\begin{tabular}{|c|c|}
\hline$E$ & $\begin{array}{l}\text { Redundancy: } \\
\text { Increased use of cohesive devices } \\
\text { enumeration } \\
\text { clarification } \\
\text { repetition } \\
\text { restatement } \\
\text { rhetorical questions } \\
\text { highlighting }\end{array}$ \\
& \begin{tabular}{c} 
Collocations \\
\hline
\end{tabular}
\end{tabular}

\section{Collocations}

The other way of increasing redundancy is by the use of collocations as mentioned in the table $\mathrm{E}$ (above). Collocations make the listener's task easier in at least two different ways. In the first place, these set, formulaic phrases, serve "a maintaining, stabilising role within communication" (Carter 1987). Quoting Yorio, Carter writes, 
[these forms] make communication more orderly because they are regulatory in nature. They organise actions and facilitate choices, thus reducing the complexity if the communicative exchanges. should not just use but overuse redundancy. We are saying that he should use more enumeration, clarification, collocation than that to be found in the typical native speaker model. In other words, we should teach a language that is in some sense atypical or artificial. Can this be acceptable of appropriate? Isn't the only acceptable model that of the native speaker? We would argue that this objection is not valid. Without going into the argument developed by Taylor (1991) that native speaker phonology is not necessarily the most comprehensible, even among native speakers, we are suggesting that in any case, the learner should not adopt the model of the native speaker. We are suggesting that to do this would be a misunderstanding of the nature of language. The only appropriate model for him is one that is based on his communicative requirements. Language is a dynamic system, appropriateness cannot be defined in the abstract by reference to an idealised native speaker model. Appropriateness in language is to be evaluated in terms of the communicative situation, that is to say a compromise between the communicative requirements and the communicative possibilities. The reduced intelligibility of the learner is a linguistic fact and as such must necessarily enter into the defining factors of what the appropriate target model should be.

\section{BIBLIOGRAPHY}

Brown, G. 1977. Listening to Spoken English. London: Longman.

Carter, R. 1987. Vocabulary. London: Allen \& Unwin.

Eastman, J. 1991. "Learning to listen and to comprehend: the beginning stages". System 19/3, 179-187. 
Higgins, J. 1988. Language, Learners and Computers. London: Longman.

Kenworthy, J. 1987. Teaching English Pronunciation. London: Longman.

Leeson, R. 1975. Fluency and Language Teaching. London : Longman.

Pitt Corder, S. 1983. "Strategies of Communication”. In Faerch, C. and G. Kasper (eds.), Strategies in Interlanguage Communication. London: Longman.

Selinker, L. 1972. “Interlanguage”. International Review of Applied Linguistics 10.

Taylor, D. 1991. "Who speaks English to whom? The question of teaching English pronunciation for global communication". System 19/4, 425-435.

Yule, G. 1990. Review of Current Perspective on Pronunciation. System 18/1, 107-111.

\section{APPENDIXES}

\section{Appendix 1: PLOM D Transcription}

I will present you to PLOM D, which is a database programming language resulting from the integration of an object oriented database programming language and then a logic programming language. This work has be done at the Bull research centre in Grenoble, in collaboration with the Grenoble University. This work is part of the Idea-Esprit project. Our work starts with the ? because we think that object oriented database programming language have a lack in declarativity, and logic deductive programming language are very appropriate and very useful when creating a database. On the other hand the imperative programming languages are needed when developing applications.

\section{NOTES}

1. Yule (1990) mentions the neglect of pronunciation "the concentration on utterance function rather than utterance form". He suggests, however, that this was specifically a product of the 1980 s and that approaches are changing.

2. In a slightly different context, Dick Allwright (1975) illustrates teacher negligence of meaning in an analysis of classroom interaction. This is a nice example as the logic of the negligence although implicit, is quite clear. Teacher: You are a journalist for the moment. Yes? Learner: What? A what please? T: Now, Sorry? L. I have not understand. What a biologist? T: I haven't understood. L. I have not understood. T: OK. There's going to be a race...

3. The laboratory is called GETA: groupe d'études pour la traduction automatique.

4. Misplaced stresses have been underlined in the talk transcription above.

5. Elisabeth Jolivet has quite rightly pointed out that this innate configuration is not completely inalterable. Remedial elocution techniques, voice projection, articulation can be useful for certain speakers.

6. The decision not to offer remedial aid for error is difficult to make. To assuage our conscience we may wish to offer awareness exercises. 


\section{ABSTRACTS}

Speaking Skills for Scientific English is the third book in the Minimum Competence in Scientific English (MCSE) series. It is designed to help those preparing to present papers or research results in English improve their communicative efficiency. However, owing to lack of time, pronunciation is often one of the first casualties in language courses, and as a result intelligibility cannot be taken for granted. After a brief outline of the background to the series MCSE, we analyse a video extract of a young researcher's presentation. This is followed by a discussion of the notions of intelligibility, redundancy and compensation strategies in a rationale for the approach we have adopted.

Speaking Skills for Scientific English est le troisième volet dans la série Minimum Competence in Scientific English(MCSE). Il a été conçu pour aider ceux qui doivent présenter leurs recherches en anglais lors des colloques à améliorer leurs communications. La prononciation, malheureusement, par manque de temps, est souvent négligée dans l'enseignement des langues. Par conséquent, l'intelligibilité ne va pas de soi. Après une esquisse de l'historique de la série MCSE, nous analysons un court extrait d'une séquence vidéo d'une jeune doctorante. Ensuite, nous abordons une discussion des notions d'intelligibilité, de redondance et des stratégies de compensation dans une défense raisonnée de notre démarche.

\section{INDEX}

Mots-clés: anglais de spécialité, cohésion, intelligibilité, prononciation, redondance, stratagème de compensation

Keywords: cohesion, compensation strategy, English for Special Purposes, intelligibility, pronunciation, redundancy

\section{AUTHORS}

\section{JONATHAN UPJOHN}

Jonathan Upjohn enseigne au Pool de langues, à l'Université Joseph Fourier, Grenoble depuis 1984. Il se consacre au développement des programmes et du matériel pour l'enseignement de l'anglais en milieu scientifique. Il est coauteur de Minimum Competence in Scientific English (Presses universitaires de Grenoble 1991), auteur de Listening Competence for Scientific English (PUG 1993) et coauteur de Speaking Skills for Scientific English (PUG 1997). jonathan.upjohn@orange.fr

\section{DIANA AMADIS}

Diana Amadis, RSA, Dip. TEFLA, actuellement doctorante à l'Université Grenoble 2, est coauteur de Speaking Skills for Scientific English (Presses universitaires de Grenoble 1997). 


\section{MARIE-HÉLÈNE FRIES-VERDEIL}

Marie-Hélène Fries-Verdeil, coauteur de Speaking Skills for Scientific English (Presses universitaires de Grenoble 1997), enseigne dans la même équipe pédagogique et s'intéresse particulièrement à la publicité à caractère scientifique et technique. Marie-Helene.Fries@ujf-grenoble.fr 